\title{
Isovaleryl-CoA Dehydrogenase Activity in Isovaleric Acidemia Fibroblasts Using an Improved Tritium Release Assay
}

\author{
DAVID B. HYMAN ${ }^{1}$ AND KAY TANAKA
}

Yale University School of Medicine, Department of Human Genetics, New Haven, Connecticut 06510

\begin{abstract}
Isovaleric acidemia is a disorder of leucine metabolism caused by a deficiency of isovaleryl-CoA dehydrogenase. At least two clinical subgroups of patients exist: a severe form, in which symptoms occur within the 1 st wk of life, and a milder variant in which manifestations develop later in life. We developed a modified version of the tritium release assay to accurately measure residual isovaleryl-CoA dehydrogenase activity in fibroblasts from patients with both forms of isovaleric acidemia. In the modified assay, specific isovaleryl-CoA dehydrogenasecatalyzed tritium release from $\left[2,3-{ }^{3} \mathrm{H}\right]$ isovaleryl-CoA was determined by including an inhibitor of isovaleryl-CoA dehydrogenase, (methylenecyclopropyl)acetyl-CoA, in one of the tubes in paired assays, to determine the nonspecifically released ${ }^{3} \mathrm{H}_{2} \mathrm{O}$. Residual activities of the nine isovaleric acidemia lines tested ranged from 0 to $0.67 \mathrm{pmol}$ ${ }^{3} \mathrm{H}_{2} \mathrm{O} / \mathrm{min} / \mathrm{mg}$ protein (controls $19.4 \pm 8.0$ ). The three lines from mildly affected individuals all had no detectable activity, whereas the severe cases had a mean of $0.41 \mathrm{pmol}$ ${ }^{3} \mathrm{H}_{2} \mathrm{O} / \mathrm{min} / \mathrm{mg}$ protein. Normal human fibroblast isovaleryl-CoA dehydrogenase had a $\mathrm{K}_{\mathrm{m}}$ for isovaleryl-CoA of $22 \mu \mathrm{M}$, with a $\mathrm{V}_{\max }$ of $51 \mathrm{pmol}{ }^{3} \mathrm{H}_{2} \mathrm{O} / \mathrm{min} / \mathrm{mg}$ protein. The $\mathrm{K}_{\mathrm{i}}$ of isovaleryl-CoA dehydrogenase by (methylenecyclopropyl)acetyl-CoA was approximately $2 \mu \mathrm{M}$. (Pediatr Res 20: 59-61, 1986)
\end{abstract}

\section{Abbreviation}

MCPA-CoA, (methylenecyclopropyl)acetyl-CoA

Isovaleric acidemia is an inherited disorder of leucine metabolism caused by a deficiency of the activity of isovaleryl-CoA dehydrogenase (EC. 1.3.99.10) $(1,2)$. Isovaleric acidemia has generally been considered to have two clinical phenotypes (3). One form (severe type) manifests as severe vomiting, lethargy, and coma, which commences within the first 2 wk of life and often causes death in the neonatal period. The other form (mild type) is characterized by recurrent milder episodes of vomiting, lethargy, and ketoacidosis. These episodes tend to begin later in life, and they are often triggered by viral or bacterial infection.

Received January 28, 1985; accepted August 21, 1985.

Correspondence and reprint requests may be addressed to $\mathrm{K}$. Tanaka, MD, Yale University School of Medicine, 333 Cedar Street, P.O. Box 3333, New Haven, CT 06510 .

This work was supported by grants from the National Institutes of Health (AM 17453) and the March-of-Dimes (1-378). D.B.H. was also supported by fellowships from the National Institutes of Health (GM 07439 and AM 06988) and a James Hudson Brown-Alexander Coxe fellowship.

1 Present address: Department of Pediatrics, State University of New York at Stony Brook, Stony Brook, NY 11794-8111.
However, this clinical classification is rather arbitrary. In those patients with the severe type who survive the first 2 wk of life with appropriate treatment, the subsequent course is not distinctly different from that of the mild type (3).

The enzyme defect in isovaleric acidemia had been assumed to be at the level of isovaleryl-CoA dehydrogenase because of the accumulation of isovaleric acid in blood (4) and isovalerylglycine in urine (5). Rhead and Tanaka (6) developed a tritium release assay for the determination of the activity of this enzyme, which measured ${ }^{3} \mathrm{H}_{2} \mathrm{O}$ formed through enzyme-catalyzed dehydrogenation of $\left[2,3-{ }^{3} \mathrm{H}\right]$ isovaleryl-CoA, and they demonstrated that residual isovaleryl-CoA dehydrogenase activity in cultured fibroblast mitochondria from five isovaleric acidemia patients was $13 \%$ of control activity (1). In contrast, the ability of isovaleric acidemia cells to oxidize $\left[2-{ }^{14} \mathrm{C}\right]$ leucine was only $1-2 \%$ of control values (7). The nature and magnitude of true residual isovalerylCoA dehydrogenase activity in isovaleric acidemia cells could not be accurately determined by the original tritium release assay.

Thus it was not possible to test whether difference in clinical severity can be related to the magnitude of the residual activity. Employing an inhibitor of several acyl-CoA dehydrogenases, MCPA-CoA $(2,8,9)$, we developed an improved assay for isovaleryl-CoA dehydrogenase to accurately determine residual isovaleryl-CoA dehydrogenase activity in fibroblasts of patients with clinically severe and mild forms of isovaleric acidemia.

\section{MATERIALS AND METHODS}

Materials. $\left[2,3-{ }^{3} \mathrm{H}\right]$ isovaleric acid-CoA $(10 \mathrm{mCi} / \mathrm{mmol})$, custom synthesized by catalytic tritiation of 3-methylcrotonic acid, was purchased from New England Nuclear (Boston, MA). MCPA acetic acid was prepared from hypoglycin A [L- $\alpha$-amino- $\beta$-(methylenecyclopropyl)propionic acid] using snake venom L-amino acid oxidase. The coenzyme $A$ derivatives were prepared via mixed anhydride synthesis. The synthesized coenzyme A esters were purified using descending paper chromatography (9).

Tissue culture. Skin fibroblasts were grown in Eagle's minimal essential media with nonessential amino acids and glutamine (Flow Laboratories, McLean, VA) supplemented with $10 \%$ fetal calf serum, and containing kanamycin and phenol red.

Enzyme assay. Isovaleryl-CoA dehydrogenase activity was assayed as follows. The assay was done in two tubes: tube A contained a complete reaction mixture including $80 \mu \mathrm{M}[2,3-$ $\left.{ }^{3} \mathrm{H}\right]$ isovaleryl-CoA; $1 \mathrm{mM}$ phenazine methosulfate; $0.1 \mathrm{mM}$ FAD; and $30 \mathrm{mM}$ potassium phosphate, $\mathrm{pH}$ 7.5. The final volume was $0.1 \mathrm{ml}$. Tube B contained $300 \mu \mathrm{M} \mathrm{MCPA}-\mathrm{CoA}$ in addition to the complete reaction mixture. The reaction was started by the addition of cell homogenate. The activity detected in tube $B$, as a measure of nonspecific ${ }^{3} \mathrm{H}_{2} \mathrm{O}$ released, was subtracted from that detected in tube A. These conditions are essentially the same as those previously described for the determination of glutaryl-CoA dehydrogenase activity (9). 


\section{RESULTS}

Using a Lineweaver-Burke plot, the normal human fibroblast isovaleryl-CoA dehydrogenase had an apparent $\mathrm{K}_{\mathrm{m}}$ for isovalerylCoA of $22 \mu \mathrm{M}$, with an apparent $\mathrm{V}_{\max }$ of $51 \mathrm{pmol}{ }^{3} \mathrm{H}_{2} \mathrm{O} / \mathrm{min} /$ $\mathrm{mg}$ protein (Fig. 1). This $\mathrm{K}_{\mathrm{m}}$ value is similar to that $(33 \mu \mathrm{M})$ of the purified rat liver isovaleryl-CoA dehydrogenase (2). The $\mathrm{K}_{\mathrm{i}}$ for MCPA-CoA could not be accurately measured by plotting reciprocal velocity versus inhibitor concentration (Dixon plot) as shown in Figure 2. This is because MCPA-CoA is a suicide inhibitor, a substrate analog which irreversibly inhibits the enzyme after it is modified by the enzyme action (10). The data in Figure 2 indicate, however, the $\mathrm{K}_{\mathrm{i}}$ of MCPA-CoA was approximately $2 \mu \mathrm{M}$.

A total of nine isovaleric acidemia cell lines were tested, a subset of the 12 isovaleric acidemia lines (three other lines were extinct by the time of this study and not available) previously found not to exhibit evidence of genetic complementation after heterokaryon fusion (11). Of these lines, three were from nonrelated patients judged to have mild clinical manifestations. The remaining six lines were from patients with acute, severe clinical manifestations. Lines 765 and 766 were siblings, but the others were from different families. Information on these patients and references to published clinical data have previously been presented (11). Seven cell lines were used as controls, including three normals, one patient with ethylmalonic/adipic aciduria, one patient with multiple carboxylase deficiency, one patient with medium chain acyl-CoA dehydrogenase deficiency, and one patient with glutaric aciduria type II.

The activity in the controls ranged from 8.0 to $39 \mathrm{pmol}^{3} \mathrm{H}_{2} \mathrm{O}$ /

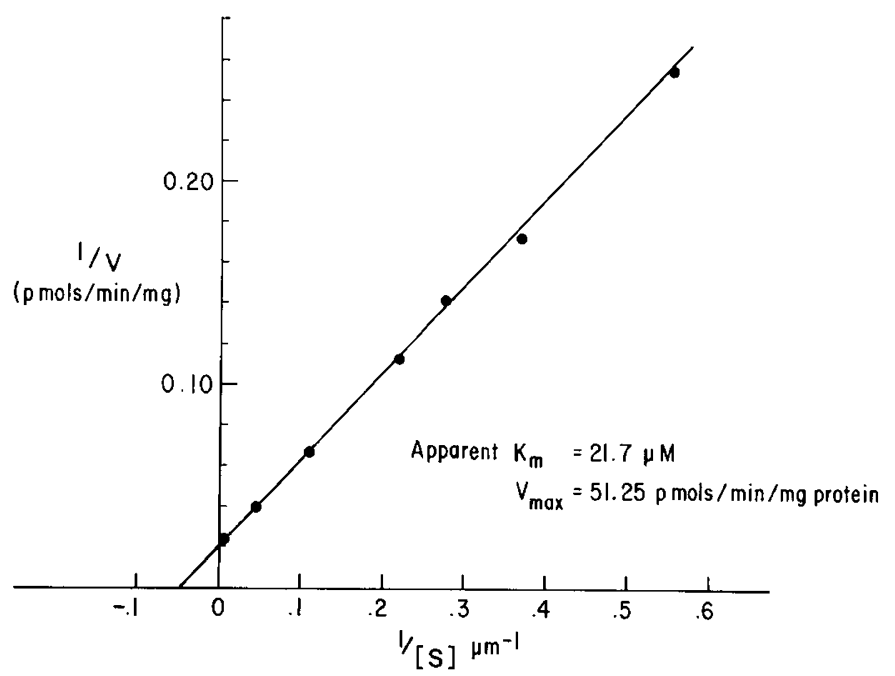

Fig. 1. Lineweaver-Burke plot of normal human fibroblast isovalerylCoA dehydrogenase activity.

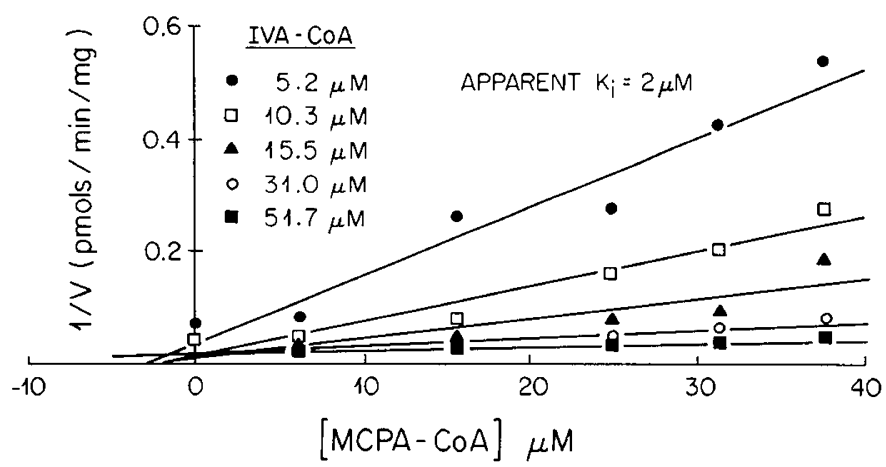

Fig. 2. Dixon plot of the reciprocals of human fibroblast isovalerylCoA dehydrogenase activity versus MCPA-CoA concentrations. $\mathrm{min} / \mathrm{mg}$ protein with a mean value of $19.4 \pm 8.0$. All three cell lines from mildly affected isovaleric acidemia children had undetectable activity, as did one line from a severely affected patient. The remaining five lines showed activities varying from $0.42 \pm 0.56$ to $0.67 \pm 0.08 \mathrm{pmol}{ }^{3} \mathrm{H}_{2} \mathrm{O} / \mathrm{min} / \mathrm{mg}$ protein (Table 1). These activities correspond to $2.2 \pm 2.9$ to $3.5 \pm 0.4 \%$ of control activity. An equal variance $t$ test demonstrated a significant $(p<0.05)$ difference between the residual activities of the two clinical subtypes, with the mild form having the lower residual activity.

\section{DISCUSSION}

The long delay between the initial identification of isovaleric acidemia (4) and the unequivocal demonstration of a deficiency of isovaleryl-CoA dehydrogenase in patients with this disorder (1) was due to the difficulty in measuring isovaleryl-CoA dehydrogenase activity in crude tissue preparations. Assay of acylCoA dehydrogenase activity had previously been done by using changes in absorbance of electron-accepting dyes, such as the combination of phenazine methosulfate and dichloroindophenol. However, the method did not give adequate sensitivity or specificity in tissue homogenates, since compounds which nonspecifically reduced the dye overwhelmed the contribution of the acyl-CoA dehydrogenases.

The tritium release assay was developed in order to measure isovaleryl-CoA dehydrogenase activity in crude tissue preparations $(1,6)$. The kinetics of this method have been studied in detail using rat liver mitochondria and partially purified isovaleryl-CoA dehydrogenase as enzyme sources (6). The activity was linear with time and amount of enzyme, and it was saturable. This assay eliminated many of the problems associated with the dye-reduction assay, but tritium release due to microsomal $\omega-1$ oxidation processes (12) and the formation of tritiated acylcarnitines, which are not adsorbed by the ion-exchange column (13), caused significant interference in measuring low activity in crude cell homogenates. It was therefore necessary to isolate mitochondria from cultured fibroblasts for the study of isovaleric acidemia (1). Our use of an MCPA-CoA inhibited blank removes from consideration the effects of microsomal oxidation, acylcarnitine formation, and nonenzymatic tritium exchange, making it possible to determine accurately isovaleryl-CoA dehydrogenase activity using whole cell homogenate.

There is less than $3.5 \%$ residual activity present in all isovaleric acidemia cell lines tested. However, a paradoxical correlation of residual activity and clinical severity was evident, which we are unable to explain. The low residual activity of isovaleryl-CoA dehydrogenating activity implies that significant amounts of isovaleryl-CoA are not metabolized by the related flavoprotein acyl-CoA dehydrogenases. Supporting this view is the observation that at $100 \mu \mathrm{M}$ substrate concentration, neither 2-methyl branched-chain acyl-CoA dehydrogenase nor any of the three

Table 1. Residual activities of isovaleryl-CoA dehydrogenase in isovaleric acidemia cells

\begin{tabular}{lccl}
\hline & \multicolumn{2}{c}{ Tritium release from $\left[{ }^{3} \mathrm{H}\right]$ isovaleryl-CoA } & \\
\cline { 2 - 2 } \multicolumn{1}{c}{ Cell line } & pmol ${ }^{3} \mathrm{H}_{2} \mathrm{O} / \mathrm{min} / \mathrm{mg}$ protein \% of control & & $\begin{array}{l}\text { Clinical } \\
\text { course }\end{array}$ \\
\hline 262 & 0 & 0 & Mild \\
502 & 0 & 0 & Mild \\
778 & 0 & 0 & Mild \\
834 & $-0.01 \pm 0.25$ & 0 & Severe \\
766 & $0.42 \pm 0.56$ & $2.2 \pm 2.9$ & Severe \\
763 & $0.44 \pm 0.50$ & $2.3 \pm 2.6$ & Severe \\
501 & $0.52 \pm 0.20$ & $2.3 \pm 1.0$ & Severe \\
765 & $0.58 \pm 0.33$ & $3.0 \pm 1.7$ & Severe \\
747 & $0.68 \pm 0.08$ & $3.5 \pm 0.4$ & Severe \\
Controls $(7)^{*}$ & $19.4 \pm 8.0$ & 100 & \\
\hline
\end{tabular}

* No. of control cell lines used. 
straight chain acyl-CoA dehydrogenases, purified from rat liver, could oxidize isovaleryl-CoA (14-16).

In patients with isovaleric acidemia, detoxification of isovaleric acid is effectively performed by the enzyme glycine- $\mathrm{N}$-acylase, which converts excess isovaleryl-CoA into the rapidly excreted and less toxic isovaleryl-N-glycine. This conjugation system is capable of handling 500-2000 mg of leucine per day in 3- to 5yr-old children and is important in preventing ketoacidosis (5). Thus, it appears that this alternate route for disposal of isovaleryl$\mathrm{CoA}$ is a more important factor in determining clinical severity than small differences in residual activities of the mutant isovaleryl-CoA dehydrogenases studied so far.

\section{REFERENCES}

1. Rhead WJ, Tanaka K 1980 Demonstration of a specific mitochondrial isovaleryl-CoA dehydrogenase deficiency in fibroblasts from patients with isovaleric acidemia. Proc Natl Acad Sci USA 77:580-583

2. Ikeda $\mathrm{Y}$ and Tanaka $\mathrm{K} 1983$ Purification and characterization of isovalerylCoA dehydrogenase from rat liver mitochondria. J Biol Chem 258:10771085

3. Tanaka K, Rosenberg LE 1983 Disorders of branched chain amino acid and organic acid metabolism. In: Stanbury JB, Wyngaarden JB, Fredrickson DS, Goldstein JL, Brown MS (eds) The Metabolic Basis of Inherited Disease, 5th ed. McGraw-Hill, New York, pp 440-473

4. Tanaka K, Budd MA, Efron ML, Isselbacher KJ 1966 A new genetic defect of leucine metabolism. Proc Natl Acad Sci USA 56:236-242

5. Tanaka K, Isselbacher KJ 1967 Isolation and identification of $\mathrm{N}$-isovalerylglycine from urine of patients with isovaleric acidemia. J Biol Chem 242:29662972
6. Rhead WJ, Hall CL, Tanaka K 1981 Novel tritium release assays for isovaleryl$\mathrm{CoA}$ and butyryl-CoA dehydrogenases. J Biol Chem 256:;1616-1624

7. Tanaka K, Mandell R, Shih VE 1976 Metabolism of $\left[1-{ }^{14} \mathrm{C}\right]$ and $\left[2-{ }^{14} \mathrm{C}\right]$ leucine in cultured skin fibroblasts from patients with isovaleric acidemia. $\mathrm{J}$ Clin Invest 58:164-172

8. Tanaka K, Miller EM, Isselbacher KJ 1971 Hypoglycin A-specific inhibitor of isovaleryl-CoA dehydrogenase. Proc Natl Acad Sci USA 68:20-24

9. Hyman DB, Tanaka K 1984 Specific glutaryl-CoA dehydrogenating activity is deficient in cultured fibroblasts from glutaric acidemia patients. J Clin Invest 73:778-784

10. Wenz A, Thorpe C, Ghisla S 1981 Inactivation of general acyl-CoA dehydrogenase from pig kidney by a metabolite of hypoglycin A. J Biol Chem 256:9809-9812

11. Dubiel B, Dabrowski C, Wetts RL, Tanaka K 1983 Complementation studies of isovaleric and glutaric aciduria type II using cultured skin fibroblasts. J Clin Invest 72:1543-1552

12. Tanaka K, Orr JC, Isselbacher KJ 1968 Identification of $\beta$-hydroxyisovaleric acid in the urine of a patient with isovaleric acidemia. Biochim Biophys Acta 152:638-641

13. Rhead WJ, Dubiel B, Tanaka K 1981 The tissue distribution of isovaleryl-CoA dehydrogenase. In: Walser M, Williamson $\mathrm{J}$ (eds) Metabolism and Clinical Implications of Branched Chain Amino and Ketoacids. Elsevier/North Holland, New York, pp 47-52

14. Ikeda Y, Dabrowski C, Tanaka K 1983 Separation and purification of five distinct acyl-CoA dehydrogenases from rat liver mitochondria. J Biol Chem 258:1066-1076

15. Ikeda Y, Tanaka K 1983 Purification and characterization of 2-methylbranched chain acyl-CoA dehydrogenase, an enzyme involved in the isoleucine and valine metabolism, from rat liver mitochondria. J Biol Chem 258:9477-9487

16. Ikeda Y, Ikeda KO, Tanaka K 1985 Purification and characterization of short chain, medium chain, and long chain acyl-CoA dehydrogenases from rat liver mitochondria: isolation of the holo- and apoenzymes and conversion of the apoenzyme to the holoenzyme. J Biol Chem 260:1311-1325 